\title{
Assessment of Passive Downdraft Evaporative Cooling Technique for Environmental Sustainability in Buildings
}

\author{
Mohammad Arif Kamal
}

\begin{abstract}
There has been a drastic increase in the use of air conditioning system for cooling the buildings all around the world. Interest on reducing emission of greenhouse gases, caused by fossil fuels to power the cooling requirements of the buildings has stimulated the interest towards adoption of passive cooling techniques for buildings. Passive downdraught evaporative cooling (PDEC) is a passive cooling technique which involves spraying of controlled volumes of microscopic water droplets into hot, dry ambient air, thereby causing it to cool and descend into a required capture zone within a building. This paper provides a study of Passive Downdraught Evaporative Cooling (PDEC) as a passive cooling technique for providing thermal comfort and its significance in energy conservation in buildings has been done. The interrelationship between sustainability and cooling needs of buildings has also been discussed. Further two applications of PDEC in contemporary architecture (Torrent Research Centre, Ahmedabad, India and New office building at Catania, Italy) have also been analyzed. Finally a critical analysis of using PDEC system in the buildings has also been done.
\end{abstract}

Keywords - Downdraft, evaporative cooling, energy conservation, PDEC.

\section{INTRODUCTION}

The last two decade has witnessed a grave energy crisis in developing countries especially during summer season primarily due to cooling load requirements of building. There has been a drastic increase in the use of air conditioning system for cooling the buildings all around the world. Increasing consumption of energy has led to environmental pollution resulting in global warming and ozone layer depletion. Hence to reduce the emission of greenhouse gases, caused by fossil fuels to power the cooling requirement of the buildings has stimulated the interest towards adoption of passive cooling techniques for buildings. Passive systems use non-mechanical methods to maintain a comfortable indoor temperature and are a key factor in mitigating the impact of buildings on the environment. Of the many different methods to reduce the cooling load passive cooling of houses and buildings is the most suitable and sustainable method. Passive downdraught evaporative cooling (PDEC) is a passive cooling technique which involves spraying of controlled volumes of

Architecture Section, Aligarh Muslim University, Aligarh, India microscopic water droplets into hot, dry ambient air, thereby causing it to cool and descend into a required capture zone within a building. From here the cool air enters the adjacent occupied spaces through carefully sized and controlled openings. With PDEC cooling process, the air temperature may be reduced by $70-80 \%$ of the wet-bulb temperature depression, providing the potential for very significant cooling in hot dry climatic regions.

\section{CoOling NeEdS OF BuILDingS AND SustainabiLITY IN ARCHITECTURE}

According to the International Institute of Refrigeration (IIR), there are more than 240 million air conditioning units installed worldwide. IIR's study shows that the refrigeration and air conditioning sectors consume about $15 \%$ of all electricity consumed worldwide [1]. It is evident that the total energy consumption of buildings for cooling purposes varies as a function of the quality of design and climatic conditions. In hot climates, commercial buildings with appropriate heat and solar protection and careful management of internal loads may reduce their cooling load down to $5 \mathrm{kWh} / \mathrm{m}^{2} /$ year, while buildings of low quality environmental design may present loads up to $450 \mathrm{kWh} / \mathrm{m}^{2} /$ year [2]. Hence the built environment has a large impact on environmental sustainability. Sustainable architecture is an approach to design where building technology is integrated with the concept design and has the potential to reduce the need for high-tech systems and reduce the energy consumption of buildings. Passive downdraught evaporative cooling (PDEC) is one of the most sustainable methods to reduce the cooling load in buildings. Since air conditioning is recognized as a significant factor in global warming and climate change, passives downdraught evaporative cooling proves to be both technically and economically viable alternative, especially in hot-dry or composite climate and where the cooling requirement is around 7-8 months in a year.

\section{Traditional Cooling Systems without Air- CONDITIONING}

Passive Downdraft Evaporative Cooling is an old technique 
was been used earlier in Islamic architecture. Evaporative cooling was extensively used in the vernacular architecture of Pakistan, Iran, Turkey and Egypt (Fig. 1). The tradition of 'cooling without air conditioning', has its origins in ancient Egypt; it subsequently spread eastwards through the Middle East and Iran to north India with the Mughal empire, and westwards across North Africa to southern Spain. In the Middle East there is a long tradition of using various techniques of evaporative cooling both within and between buildings. Wind catchers called 'malqafs' captured wind and directed it over porous water pots, causing evaporation and bringing a drop in temperature as a result of latent heat of vaporization [3]. This system maintained a balance between two important parameters of passive cooling - thermal performance and ventilation effectiveness. In this tradition, wind-catchers guide outside air over water-filled porous pots, inducing evaporation and bringing about a significant drop in temperature before the air enters the interior. In North India, the Mughal palaces and gardens exploited evaporative cooling to provide thermal relief. Thin water chutes (salsabil) and other evaporative cooling techniques were features of Mughal architecture from the thirteenth to the seventeenth centuries. The intense dry heat and dust of the summer in north India calls for the creation of an internal refuge or haven from the extremes of the external world. The diurnal swing in temperature is dampened by the mass of stone and earth, and the air is further cooled by the evaporation of water in the ventilation air flow path. This is exemplified perfectly in the beautifully atmospheric Rai Pravina Mahal in Orcha [4].

Fig. 1:

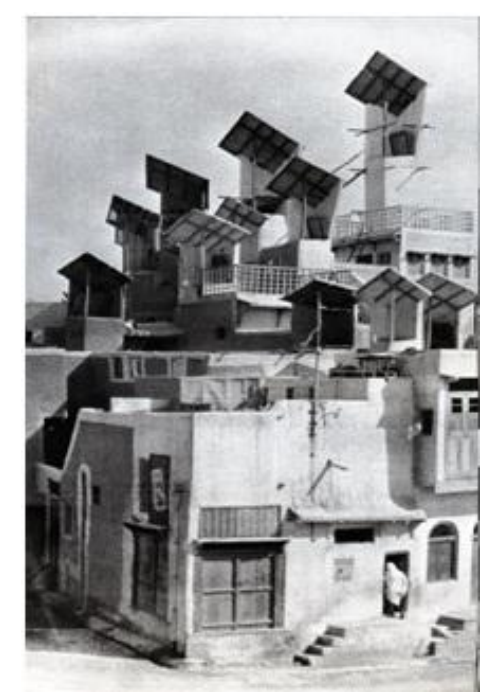

Wind Catchers in Traditional

Architecture of Sindh, Pakistan

\section{Design Concept of Passive Downdraft Evaporative COOLING (PDEC) SYSTEM}

Maintaining a comfortable environment within a building in a hot climate relies on reducing the rate of heat gains into the building and encouraging the removal of excess heat from the building. Passive-cooling techniques concentrate mainly on reducing unwanted heat gains into the building. In the twentieth century, evaporative cooling was applied in buildings throughout the world in conjunction with a mechanically driven air supply (known widely as desert coolers). Recently, attention has returned to the potential of exploiting the benefits of direct evaporative cooling while avoiding mechanical assistance by using buoyancy or wind forces to drive the air flow. In the late 1980s, a number of successful experiments were undertaken which tested the evaporation of water within a downdraught tower, hence the term Passive Downdraught Evaporative Cooling [5].

The device consists of single or multiple towers equipped with a water vapour supply placed on the top. This innovation consists of replacing the wetted pads with rows of atomisers (nozzles, which produce an artificial fog by injecting water at high-pressure trough minute orifices). During the constant injection of water, droplets descend through the tower and conditions close to saturation along its length. Cool air descends the tower and exits at its base where it is delivered to the adjacent spaces (Fig. 2). The concept is based on the relatively large amount of energy required to convert water from its liquid to gaseous form within a local thermal imbalance with subsequence differences in air density. This leads to the movement of air from a zone of high pressure, where air is hot and less dense (top of the tower) to a zone of lower pressure, where air is colder and denser (bottom of the tower). The situation of the micronisers in a tower gives rise to a naturally downdraught effect.

Fig. 2: Cross- Sectional Details of Passive Downdraft Cooling System. 


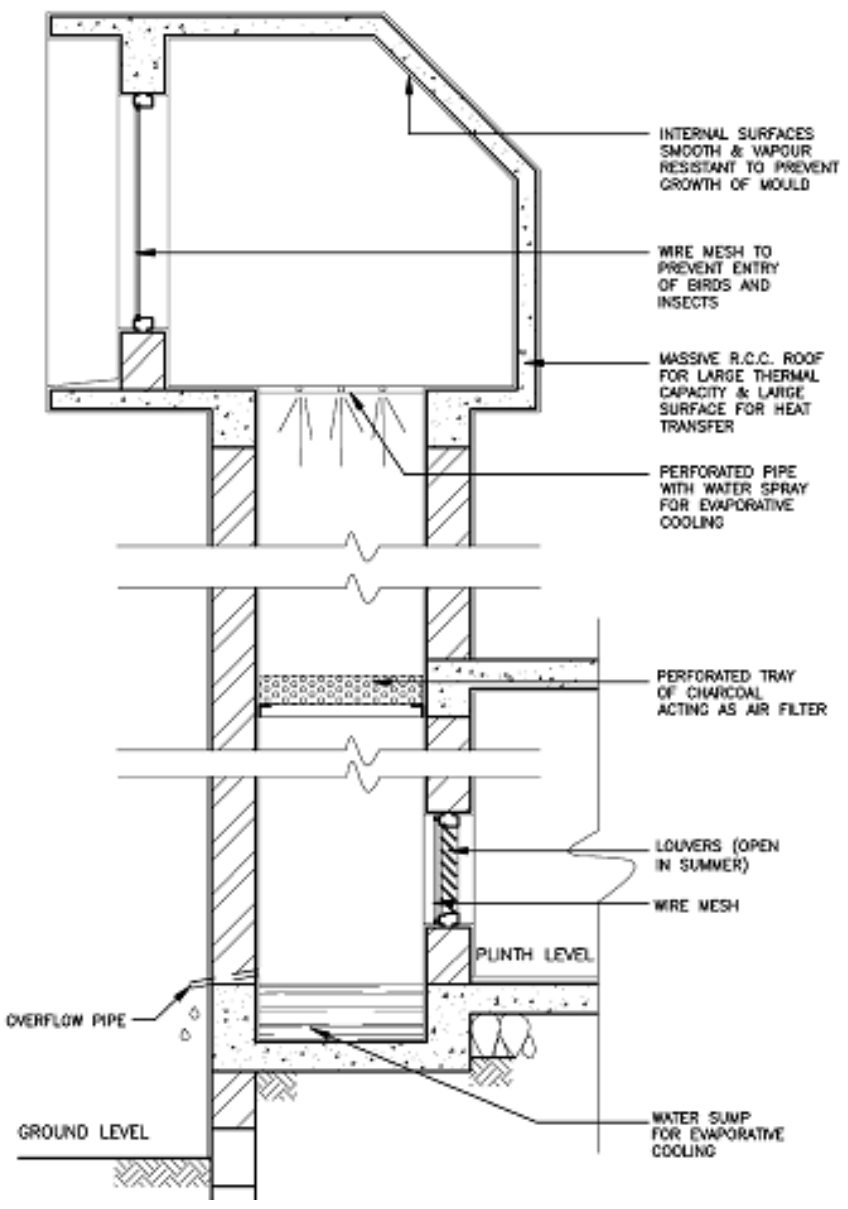

Fig. 2: Cross- Sectional Details of Passive Downdraft Cooling System.

The design of PDEC system depends on two basic factors that determine its effectiveness: (1) amount of cooling of the ambient air achieved, and (2) the rate at which this conditioned ambient air replaces the stale air within the building. The former can be easily achieved by increased airwater contact zone. This factor usually dictates the height of the tower and in turn, influences the massing of the building design. The second factor, however, requires a complex interplay of different variables to achieve an effective performance. These variables dictate the configuration of the tower termination, the positioning of multiple towers within the building, the circulation pattern within the building, and even the configuration of openings between adjacent spaces served by these towers. The temperature of the incoming ambient air drops while crossing the pads. Therefore, the height of the tower and the area of the wetted pads are not expected to have any effect on the temperature of the air in the tower in a given combination of ambient dry and wet bulb temperatures. These two system design factors affect the airflow rate, and hence the total cooling effect generated by the system [6].

\section{CONTEMPORARY APPLICATIONS OF PASSIVE DOWNDRAFT EVAPORATIVE COOLING}

Contemporary passive downdraft evaporative cooling systems consist of a downdraft tower with wetted cellulose pads at the top of the tower. Water is distributed on the top of the pads, collected at the bottom into a sump and recirculated by a pump. Certain designs exclude the re-circulation pump and use the pressure in the supply water line to periodically surge water over the pads, eliminating the requirement for any electrical energy input. In some designs, water is sprayed using micronisers or nozzles in place of pads, in others, water is made to drip. Thus, the towers are equipped with evaporative cooling devices at the top to provide cool air by gravity flow. These towers are often described as reverse chimneys. While the column of warm air rises in a chimney, in this case the column of cool air falls. The air flow rate depends on the efficiency of the evaporative cooling device, tower height and cross section, as well as the resistance to air flow in the cooling device, tower and structure (if any) into which it discharges [7].

\section{A. Case Study 1: Torrent Research Centre}

The first large-scale application of PDEC was in the Torrent Research Centre, a pharmaceutical research laboratory in Ahmedabad (Fig. 3). Designed by Abhikram Architects and completed in 1998, this project demonstrated that this approach to cooling could be applied to a large, complex laboratory building [8]. The total built up area of the complex is approximately 20,000 Sq. Mts. $72 \%$ of the central building has achieved human comfort conditions using Passive Downdraft Evaporative Cooling (PDEC), it has been able to establish extremely low levels of energy consumption, as well as considerably decreased Carbon Dioxide emissions per square meter of area. Around 200 Metric tons of Airconditioning load is saved. The performance has been consistent over the past eleven years of its use. The entire cost of the building will be recovered from the electrical savings alone, in 13 years of operation [9].

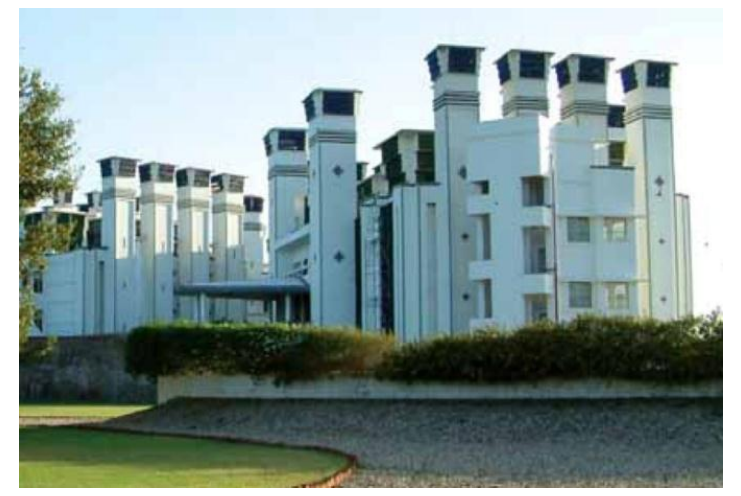

Fig. 3: Passive Downdraft Evaporative Cooling in Torrent Research Centre, Ahmedabad, India

Measurements of air temperature and relative humidity in different parts of the building in April 1998 revealed that very significant cooling and high air change rates were achieved. 
Peak temperatures of $27^{\circ} \mathrm{C}$ in the ground floor laboratory, and $29^{\circ} \mathrm{C}$ at first floor, were achieved when the external maximum reached $38^{\circ} \mathrm{C}$. Over the same period, air change rates of 9 per hour on the ground floor and 6 per hour at first floor were recorded. The staff reported that during the summer (February-June) the laboratories are comfortable without fans and are not stuffy or smelly, as most chemistry labs are, even when air conditioned. During the monsoon (July-September), the evaporative cooling system is not operated, of course, so ceiling fans are used to enhance comfort for these two to three months. In the first year since its occupation, the Torrent Research Centre was reported to have used approximately $64 \%$ less electrical energy than the equivalent conventionally air-conditioned building [10].

\section{B. Case Study 2: Office Building in Catania, Italy}

A high performance example of PDEC is the design proposed by Mario Cucinella Architects for the new office in Catania, Italy (Fig. 4). The design consists of a $27 \mathrm{~m}$ wide by $70 \mathrm{~m}$ long, 4 storey office building punctured by nine $3 \mathrm{~m}$ diameter glazed cylindrical PDEC towers. These towers protrude above the roof of the building by about $6 \mathrm{~m}$. The microniser spray and baffles to avoid wind effects were located in this tower head region. Air entered each of the 3 floors and the ground floor through high level openings in each PDEC tower leaving the building via the highly glazed double-skin facade. The main idea was to create a number of PDEC towers that passed through the building vertically. Each tower cooled the air in the adjacent area when needed (Fig. 5). The towers were also used for night ventilation and to bring daylight into a deep plan space [11].

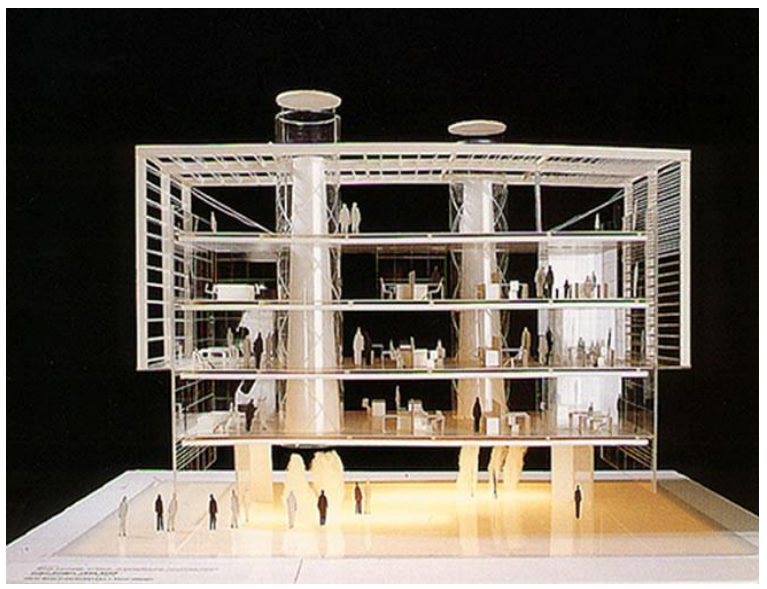

Fig. 4: The New Office Building in Catania, Italy designed by Mario Cucinella Architects.

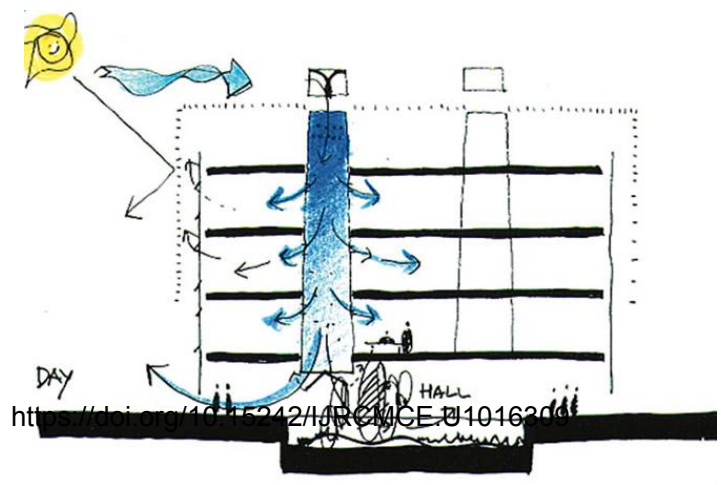

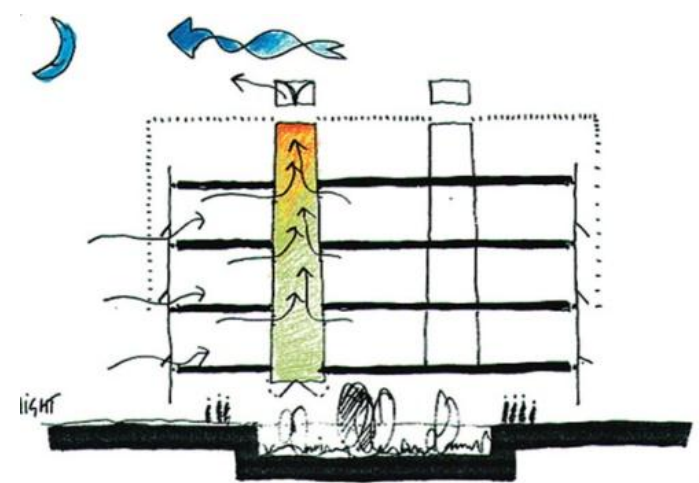

Fig. 5 (A) \& (B): The Day And Night Functioning Of PDEC In Office Building In Catania, Italy.

Architect Mario Cucinella, a partner in a research group funded by European Commission's Joule program, explored how to apply this historic, passive cooling technique to commercial buildings in southern Europe's hot, dry regions [12]. Thermal analysis of the Catania office building was undertaken by ESII using PASSPORT-Plus in which a PDEC tower model had been incorporated and the CFD program FLUENT.

The thermal simulation analyses indicated that:

- the tower height should be $6 \mathrm{~m}$ above the building roof;

- under this system, peak cooling loads could be reduced by a third, from $82 \mathrm{~W} /$ square meter to $58 \mathrm{~W} /$ square meter, compared with the original single atrium design.

- with an external air temperature of $29^{\circ} \mathrm{C}$ and an internal heat load of $30.7 \mathrm{~W} / \mathrm{m} 2$ thermally acceptable conditions could be obtained on the office floors using PDEC;

- PDEC alone could not maintain comfort throughout the year and so had to be supported by a mechanical cooling system;

\section{PERFormance ANALysis of PASSIVE DOWNDRAFT EVAPORATIVE COOLING SYSTEM}

Through evaporative cooling, the ambient air can potentially be cooled down to the dew point temperature simply by saturating it with moisture. This type of cooling is thus particularly efficient in relatively dry climates. But in humid climates is also possible to generate cooled air flow through evaporative cooling [13]. PDEC systems have been used with various types of cooling devices such as, spray devices (pressure and ultrasonic nozzles), aspen fibre pads, corrugated cellulose pads, etc. The performance analysis would thus vary depending on the evaporating cooling facilities provided in the tower. Aspen pads cause a high pressure drop relative to sprays and corrugated media, but they are low in cost. Spray devices may require efficient mist 
eliminators for removing fine droplets from the air because mist impedes air flow [14]. PDEC can avoid the need for ductwork, fans and suspended ceilings, thereby reducing the overall height of buildings. In less severe climates, or in less demanding buildings, PDEC might avoid the need for airconditioning entirely. PDEC provides $100 \%$ fresh, cool air with no re-circulation - as is often the case in air-conditioned buildings. PDEC ought, therefore, to provide an environment with high air quality. In a research project funded by the European Commission, Mario Cucinella Architects and partners, an assessment of the Potential application of Passive Downdraught Evaporative Cooling in Southern Europe was done. The Table 1 below summarises the stock areas and potential energy savings of four European countries and shows that energy savings could be around $1.5 \%$ to $2.5 \%$ of the national annual electricity consumption [15].

TABLE I:

POTENTIAL ENERGY SAVINGS THROUGH PDEC

\begin{tabular}{|c|c|c|c|c|c|c|}
\hline Country & $\begin{array}{l}\text { Commercial } \\
\text { buildings } \\
\text { area millions } \\
\text { m2 }\end{array}$ & $\begin{array}{l}\text { National } \\
\text { electricity } \\
\text { consumption } \\
\text { millions KWh }\end{array}$ & $\begin{array}{l}\text { PDEC } \\
\text { potential } \\
\text { energy } \\
\text { savings } \\
\text { millions } \\
\text { KWh }\end{array}$ & $\begin{array}{l}\text { Energy } \\
\text { savingas \% } \\
\text { of national } \\
\text { electricity } \\
\text { consumption }\end{array}$ & $\begin{array}{l}\text { Reduction } \\
\text { in CO2 } \\
\text { emissions } \\
\text { tonnes,pa }\end{array}$ & $\begin{array}{l}\text { Potential } \\
\text { value of } \\
\text { energy } \\
\text { saving } \\
\text { pa euro } \\
\text { million }\end{array}$ \\
\hline Greece & 39 & 46,099 & 1,124 & $2.44 \%$ & 766,596 & 85.4 \\
\hline Spain & 116 & 201,159 & 3,341 & $1.66 \%$ & $1,472,654$ & 257.9 \\
\hline Italy & 161 & 283,737 & 4,637 & $1.63 \%$ & $2,809,643$ & 490.4 \\
\hline Portugal & 25 & 41,146 & 720 & $1.75 \%$ & 391,414 & 59.0 \\
\hline
\end{tabular}

\section{Limitations Of PASSIVE DOWNDRAFt EVAPORATIVE COOLING (PDEC)}

The hardness of the water is a significant factor, therefore water quality has to be good otherwise nozzles will block. High pressures $(>40$ Bar) are required to minimize water droplet size and maximize evaporation, which implies more expensive pumps and plumbing. The risk of microbiological contamination of the water supply to the misting nozzles must also be minimized. This can be addressed by a combination of design measures (including the use of UV filters in the supply line to the micronizers), regular maintenance, and testing, but it would clearly be better if this was not an issue. In many parts of the world the potential disadvantages of using micronizers (risks of microbiological contamination, blockage of micronizers, high-pressure stainless-steel plumbing fittings etc.), are a powerful disincentive. 'Low-Tech' solutions may be more appropriate in locations where water quality is poor, or where high-pressure plumbing is unfamiliar. The practical integration of such systems within the building envelope is fundamental to the feasibility of this approach.

\section{CONCLUSION}

The use of air conditioning has increasingly penetrated the market during the last few years and greatly contributes in the upsurge of absolute energy consumption due to improving standards of life and increasing world population. Since air conditioning is recognized as a significant factor in global warming and climate change, passives downdraught evaporative cooling proves to be both technically and economically viable and is competitive against conventional air-conditioning, especially in India where most of the population resides in hot and dry or composite climate and where the cooling requirement is around seven months in a year. The PDEC technique has only recently been applied to buildings, but has enormous potential to displace the need for conventional air conditioning. Incorporation of PDEC would certainly reduce our dependency on artificial means for thermal comfort and minimize the environmental problems due to excessive consumption of energy and other natural resources and will evolve a built form, which will be more climate responsive, more sustainable and more environmental friendly buildings of tomorrow.

\section{REFERENCES}

[1] International Institute of Refrigeration, 'Report on Industry as a partner for sustainable development - refrigeration,' IIR, Paris, 2002.

[2] M. Santamouris and E. Dasalaki, 'Case Studies - In Natural Ventilation,' London, James and James Science Publisher, 1998.

[3] B. Ford, Passive downdraught evaporative cooling: principles and practice, Architecture Quarterly, Vol. 5, No. 3. 2001.

[4] B. Ford and M. Hewitt, Cooling without Air Conditioning - Lessons from India, Architecture Quarterly, Vol. 1, No. 4, pp. 60 - 69, 1996

https://doi.org/10.1017/s1359135500003080.

[5] Ibid 3

[6] B. Givoni, Passive and low energy cooling of buildings, New York, Van Nostrand Reinhold, 1994.

[7] T. L. Thompson, N. V. Chalfoun and M. R. Yoklic, Estimating the performance of natural draft evaporative coolers, Energy Conversion and Management, 1994

https://doi.org/10.1016/0196-8904(94)90022-1.

[8] B. Ford., N. Patel., P. Zaveri and M. Hewitt, Cooling without Air Conditioning: The Torrent Research Centre, Proceedings of World Renewable Energy Congress, Florence, Pergamon, 1998.

[9] Abhikram, Green by design, Home Review, Marvel Infomedia Pvt. Ltd., Mumbai, 2009.

[10] Ibid 3 .

[11] F. Elizabeth and B. Ford, Recent Developments in Passive Downdraught Cooling - An Architectural Perspective, James and James Science Publishers, London, U.K. 1999.

[12] M. Cucinella, F. Elizabeth, B. Ford et al, The Application of Passive Downdraught Evaporative Cooling to Non-domestic Buildings, Final Publishable Report, De Montfort University, UK 1998.

[13] S. Yajima and B. Givoni, Experimental performance of the shower cooling tower in Japan, Renewable Energy, Volume 10, issue 2/3, pp. 179$183,1997$.

https://doi.org/10.1016/0960-1481(96)00060-2

[14] Ibid 7.

[15] ALTENER (Jan. 2012). Solar Passive heating and Cooling: Market Assessment of the Potential Application of Passive Downdraught Evaporative Cooling in Southern Europe, Available: http:// www.phdc.eu/index.php?id=10 